\title{
IgDK Multiple Myeloma Presenting as Unilateral Proptosis
}

\author{
Joseph Y. Chu, Anthony J. Lewis and Donald H. Cowan
}

\begin{abstract}
A 72-year-old woman presented with painful proptosis of the right eye and a large destructive tumour of the middle cranial fossa. A diagnosis of IgDK multiple myeloma was made, based on histopathologic and immunologic studies of the biopsy. Biochemistry and bone marrow examination further confirmed the myeloma as IgDK type. The clinical, radiological, and pathological findings are presented. The patient was treated with radiotherapy with satisfactory results.
\end{abstract}

RÉSUMÉ: Myelome multiple IgDK se présentant par une proptose unilaterale Nous rapportons le cas d'une femme de 72 ans qui s'est présentée avec une proptose douloureuse de l'oeil droit et une grosse tumeur destructrice de la fosse crânienne moyenne. Le diagnostic de myélome multiple type IgDK fut posé sur la base d'études histopathologiques et immunologiques de la biopsie. La biochimie et l'examen de la moelle osseuse ont également confirmé le type de myélome. Nous en présentons les aspects cliniques, radiologiques et pathologiques. La patiente fut traitée par radiothérapie avec des résultats satisfaisants.

Can. J. Neurol. Sci. 1985; 12:69-72

Multiple myeloma is a plasma cell dyscrasia frequently associated with multiple lytic bone lesions, anemia, monoclonal immunoglobulin in the serum, and commonly monotypic light chains in the urine. It is known that IgD multiple myeloma comprises about $2 \%$ of all cases of myeloma and that in $89 \%$ of these cases, the light chains are of lambda type (Pruzanski and Rather, 1970). Orbital involvement by myeloma occurs in $0.3 \%$ of cases (Hayes et al., 1980) and the majority are unilateral. We recently encountered a patient with $\operatorname{IgD}$ multiple myeloma presenting with unilateral painful proptosis.

\section{CaSe Report}

A 72-year-old woman was admitted to Sunnybrook Medical Centre on March 6, 1984 with a two month history of painful proptosis of the right eye. She had complained of severe low back pain six months prior to admission, at which time $x$-rays of the lumbosacral spine revealed diffuse bone thinning with compression of the Ll vertebra. A provisional diagnosis of osteoporosis was made, and she was treated with acetaminophen, codeine, calcium supplement, and Naprosyn. Over the next six months, she developed anorexia, nausea and vomiting, and lost $13.6 \mathrm{~kg}$.

Examination on admission revealed a thin elderly woman with a slightly tender, soft tissue mass above the right zygoma. There was right-sided exophthalmos (Hertel exophthalmometer reading of $21 \mathrm{~mm}$. on the right and $12 \mathrm{~mm}$. on the left). Corrected visual acuity on the right was 20/100, and on the left 20/50. Adduction and upward gaze of the right eye was limited. The optic fundi were normal, and the corneal reflexes were intact. The remainder of the neurological examination was normal. There was tenderness of the upper lumbar vertebrae. Otherwise, the general physical examination was normal.

Orbital $x$-ray showed destruction of the greater and lesser wings of the right sphenoid bone. Orbital ultrasound demonstrated a $1.7 \mathrm{~cm}$. solid mass posterior to the orbit, lateral to the lateral rectus muscle and displacing it medially. Contrast-enhanced CT scan showed a large uniformly enhancing tumour on the right side destroying the floor of the middle cranial fossa, and extending upward to displace the temporal lobe. There was also destruction of the lesser wing of the sphenoid, postero-lateral orbital wall, and a portion of the lateral orbital roof. Inferiorly, the tumour extended along the pterygoid muscles and destroyed the pterygoid plates, with extension into the nasal cavity, nasopharynx, and sphenoid sinus (Figure 1). Skeletal survey showed compression of $L 1$ vertebral body and loss of posterior elements of L5 (Figure 2). There were also multiple lytic bone lesions of the skull, both humeri, both femurs, and ribs.

A biopsy was taken from the right temporal bone where it was eroded by grayish tumour. The histologic and electron microscopic appearance was typical of multiple myeloma. Immuno-peroxidase staining revealed that it was of the lgDK type (Figure 3 ).

The hemoglobin was $11.0 \mathrm{~g} / \mathrm{l}$ with normal leukocytes and platelets. The BUN was $5 \mathrm{mmol} / /(\mathrm{N}=3.0 \cdot 7.0 \mathrm{mmol} / \mathrm{l})$, creatinine $145 \mathrm{mmol} / \mathrm{l}(\mathrm{N}$ $=50 \cdot 120 \mathrm{mmol} / \mathrm{l})$, and serum calcium $2.57 \mathrm{mmol} / \mathrm{l}(\mathrm{N}=2.20-2.60$ $\mathrm{mmol} / \mathrm{l})$. The total serum protein was $51 \mathrm{~g} / \mathrm{l}(\mathrm{N}=60-80 \mathrm{~g} / \mathrm{l})$ and albumin $31 \mathrm{~g} / \mathrm{l}(\mathrm{N}=35-50 \mathrm{~g} / \mathrm{l})$. Protein electrophoresis showed slight increase in $\approx 2$ globulin without a paraprotein peak. Quantitative immunoglobulins in the serum revealed $\operatorname{lgG}=6.7 \mathrm{~g} / \mathrm{l}(\mathrm{N}=5-15 \mathrm{~g} / \mathrm{l}), \mathrm{lgA}=1.25 \mathrm{~g} / \mathrm{l}(\mathrm{N}=$ $0.7-2.9 \mathrm{~g} / \mathrm{l}), \mathrm{IgM}=0.8 \mathrm{~g} / \mathrm{l}(\mathrm{N}=0.7-2.5 \mathrm{~g} / \mathrm{l})$ and $\mathrm{lgD}=2.2 \mathrm{~g} / \mathrm{l}(\mathrm{N}=0.01$ $-0.04 \mathrm{~g} / \mathrm{l})$. The 24 hour excretion of protein in the urine was $3.2 \mathrm{gm}$. Immunoelectrophoresis of the urine revealed free kappa light chains.

From the Department of Pathology, Division of Neuropathology and the Department of Medicine, Division of Haematology, Sunnybrook Medical Centre, University of Toronto

Received July 19, 1984. Accepted in revised form October 12, 1984

Reprint requests to: Dr. A. J. Lewis. Division of Neuropathology, Department of Pathology. Sunnybrook Medical Centre. Toronto, Ontario. Canada M4N 3M5 


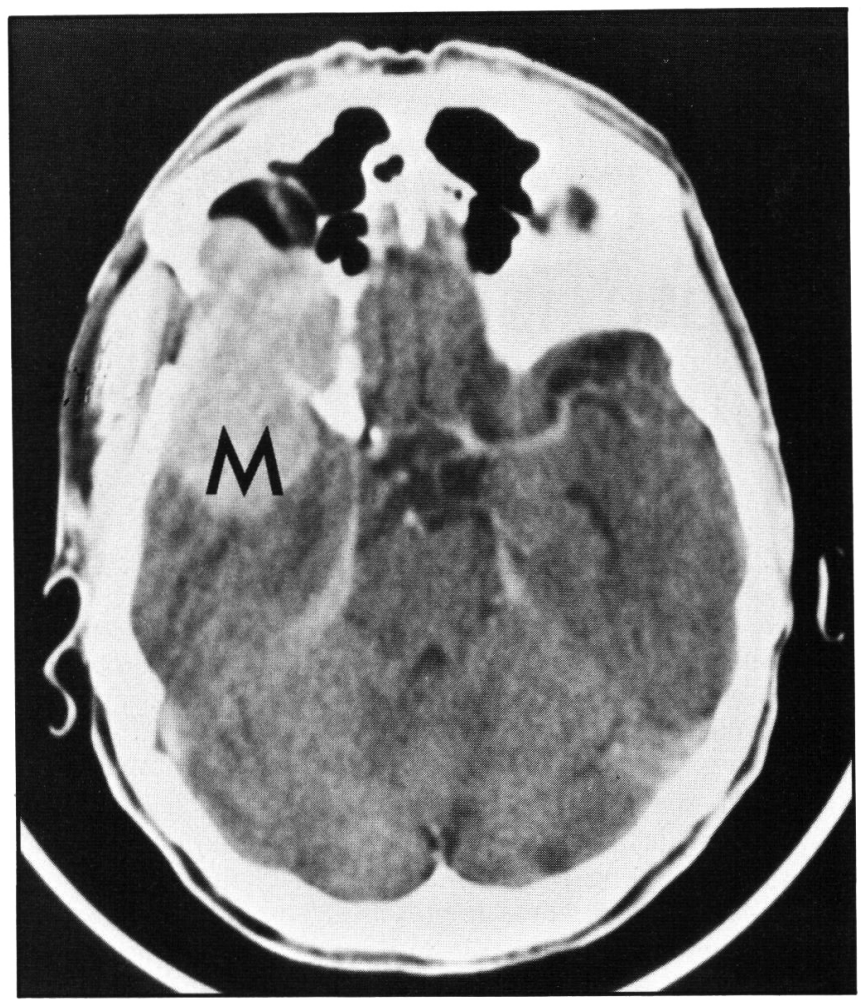

A

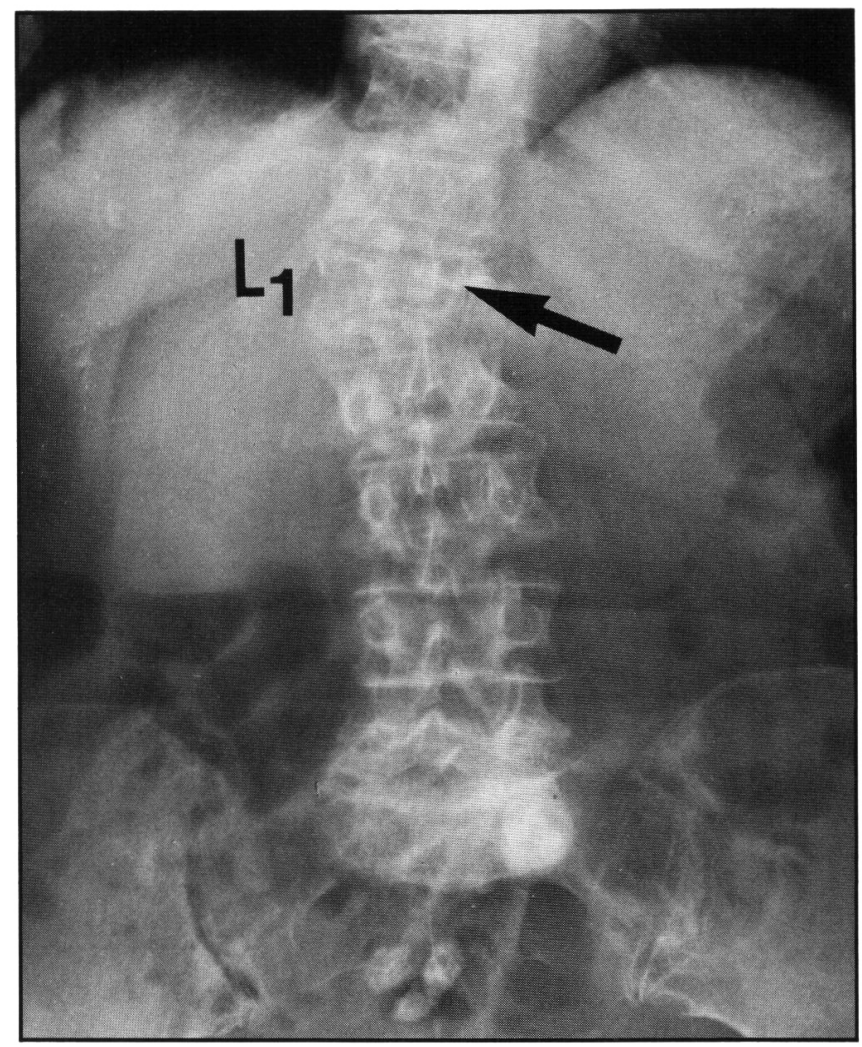

Figure 2-Radiograph showing diffuse osteoporosis of lumbosacral spine with compression of $L I$ vertebral body and loss of the pedicles (arrow). There is also loss of inferior end plate of $L 5$.

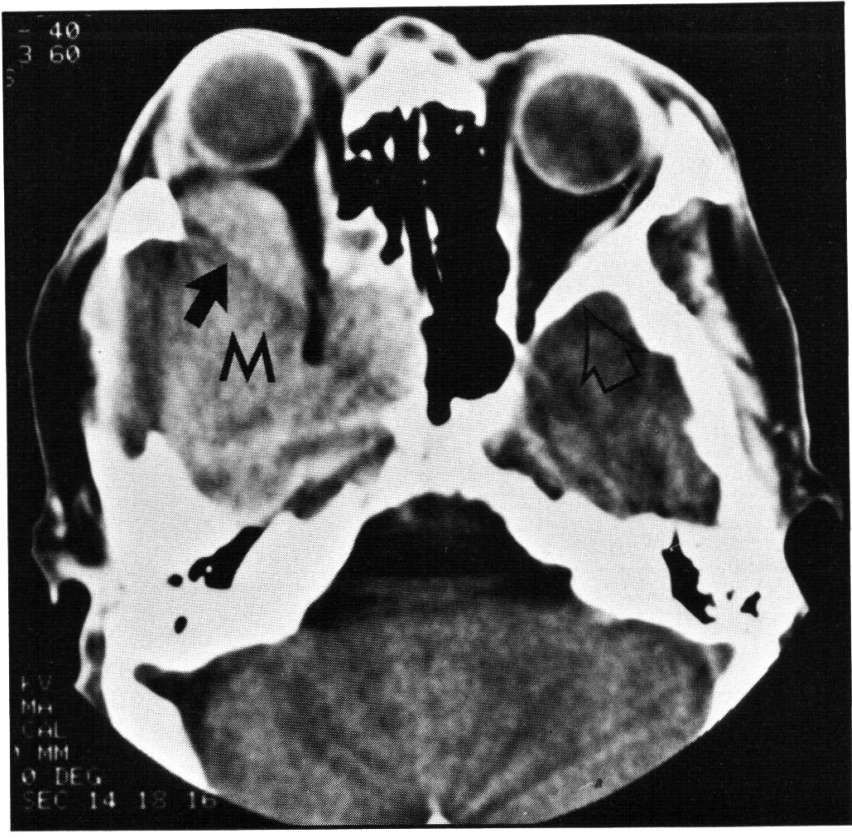

B

Figure 1-Contrast-enhanced CT scan. A) Showing bony erosion of sphenoid wing and temporal bone with extension into middle cranial fossa $(M)$. $B)$ Magnified view of orbits and sphenoid wings. Solid arrow points to destroyed lateral and medial orbital walls compared to normal left side (open arrow).

Bone marrow aspirate demonstrated diffuse infiltration by plasma cells. Cytoplasmic immunofluorescent staining confirmed IgD kappa type myeloma (Figure 4).

\section{Discussion}

Neurological complications in multiple myeloma are relatively frequent, the most common being extradural spinal cord compression (Brenner et al., 1982; Silverstein and Doniger, 1963). According to Clarke (1954), cranial or intracranial myelomas can be broadly classified into three clinical groups:

(I) Syndromes of cranial nerve palsies - unilateral or bilateral VI, VII and unilateral I (Woodruff and Ireton, 1982).

(II) Intracranial tumour syndromes with or without involvement of skull bones (Weiner et al., 1966; Stark and Henson, 1981).

(III) Intra-orbital tumour syndromes (Clarke, 1953).

The present case appeared to be a myeloma arising from the body of the sphenoid wing, with extensive destruction of the nearby bone structures and compression of the right temporal lobe. The clinical picture was that of a retro-orbital mass lesion which, unlike most meningiomas, had produced extensive bony destruction. Bilateral orbital infiltration by myeloma has been reported by Hayes et al. (1980) in a patient with IgG myeloma and by Trecan et al. (1977) in a patient with IgM myeloma.

IgD myeloma (Fahey and Carbine, 1968) had been estimated to comprise about $2 \%$ of all myelomas (Jancelewicz et al., 1975). There is a male predominance (Fishkin et al., 1970) and $65 \%$ of 133 patients reported were younger than 60 years of age at diagnosis (Jancelewicz et al., 1975). As compared to IgA, IgG, and IgM myelomas, $90 \%$ of the IgD myelomas are of the lambda type (Pruzanski and Rother, 1970). They have a higher 


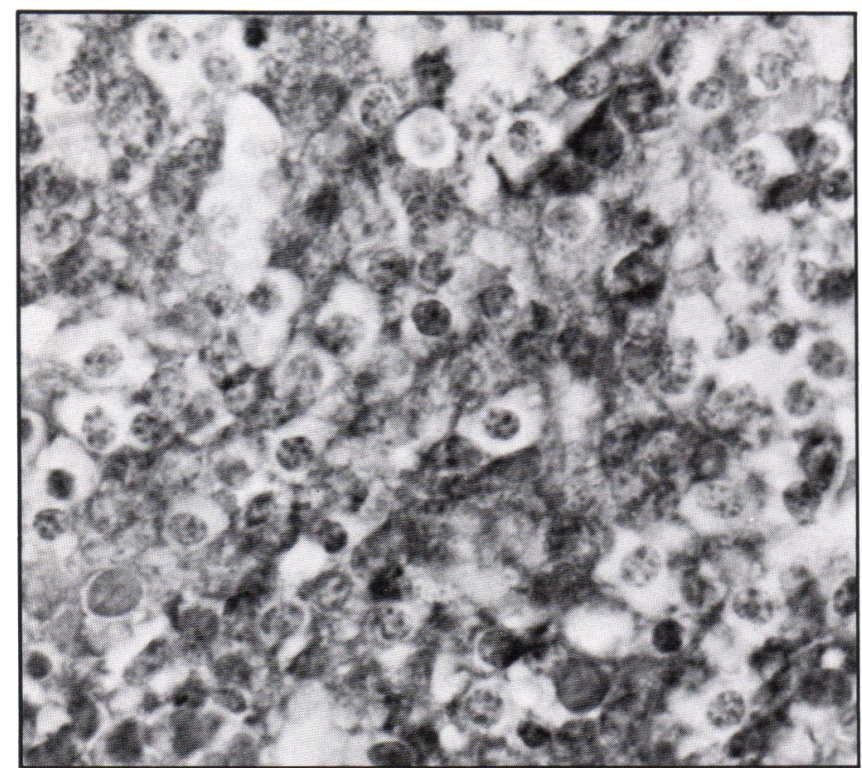

A

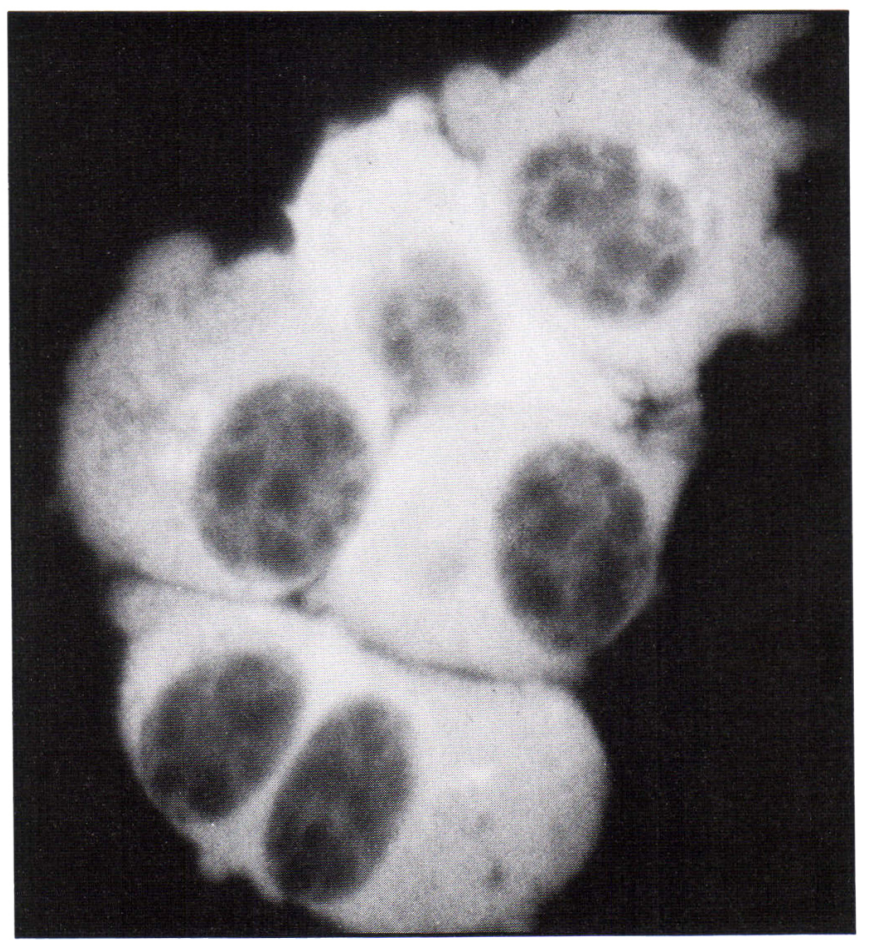

A

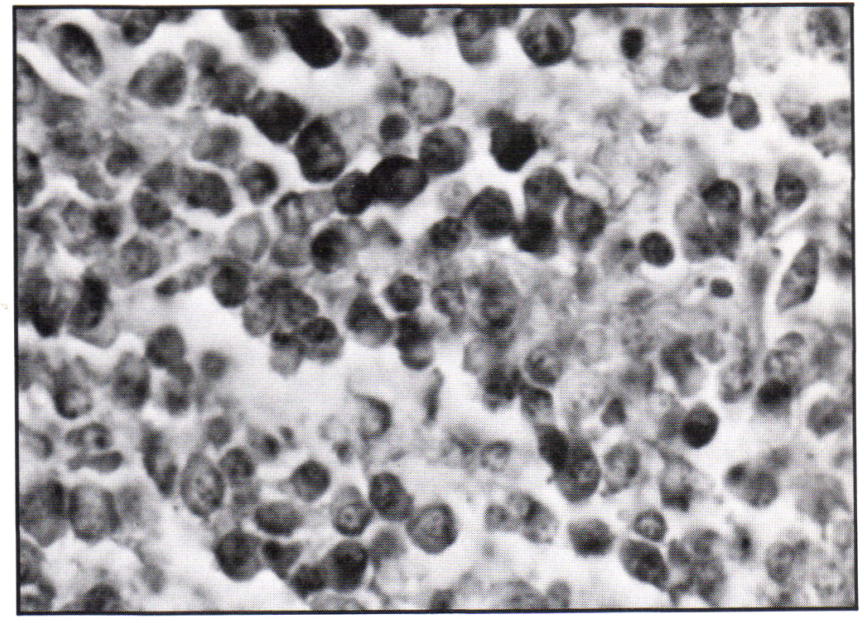

B

Figure 3 - Surgical biopsy from right temporal bone. A) Cytoplasmic immunoperoxidase staining for $\lg D(x 160)$. B) Cytoplasmic immunoperoxidase staining for $K$ light chains $(x 160)$.

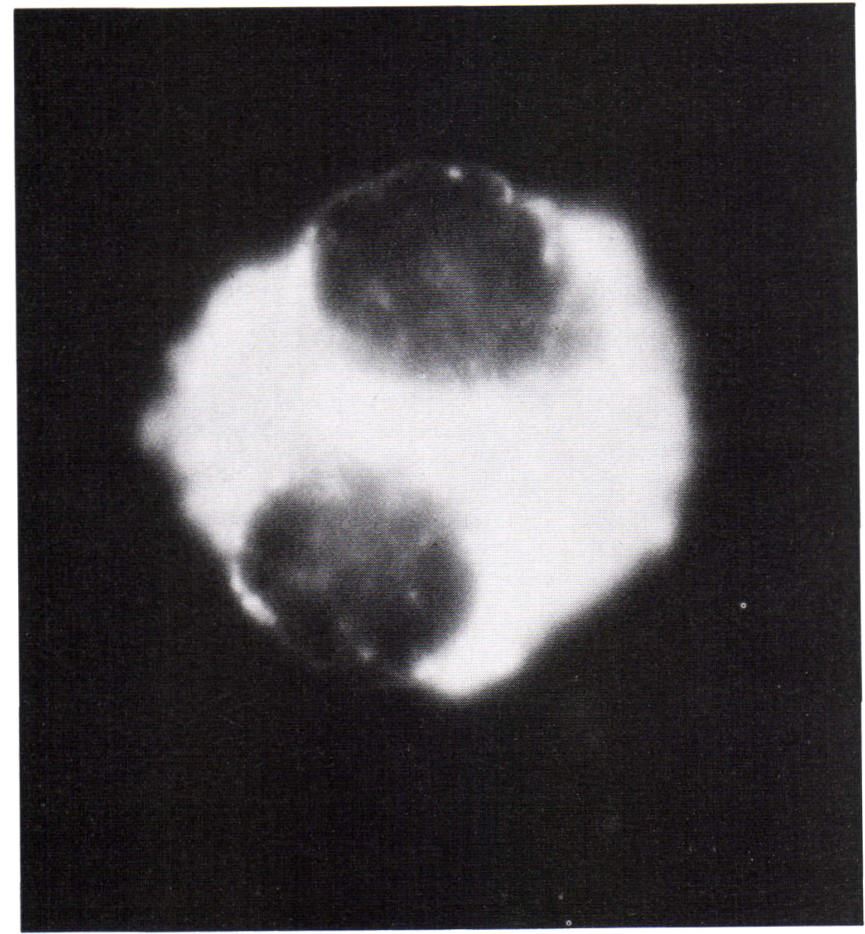

B

Figure 4-Bone marrow aspirate. A) Cytoplasmic immunofluorescent staining for $1 \mathrm{gD}$. (I000X). B) Cytoplasmic immunofluorescent staining for $K$ light chains. (1000X).

incidence of extra-osseous spread, and are frequently associated with severe anemia, azotemia and amyloidosis (Jancelewicz et al., 1975). The mean survival is 13.7 months from diagnosis, and deaths are usually due to infections or renal failure.

Unilateral proptosis was observed in 6 of 133 patients with IgD myeloma, and in one of these patients there was associated ocular muscle paralysis (Jancelewicz et al., 1975). IgD myeloma has also been reported in a patient with sphenoid sinus involvement (Humphrey et al., 1983) and in two patients with menin- geal infiltration associated with increased CSF IgD/albumin ratio (Schulman et al., 1980).

The present case is unusual in that the patient is female, older than age 60 , and the paraprotein light chain is of the kappa type. As yet, there is no clinical evidence of amyloidosis, and she has only slight anemia and mildly impaired renal function. The difference in prognosis between patient with IgD myeloma exhibiting kappa vs. lambda light chains is as yet unknown. In general, patients with myeloma of the kappa chain type appear 
to have a slightly longer mean survival time, mean 28.3 years vs. 18.3 years for the lambda type (Jancelewicz et al., 1975).

This case serves to illustrate that retro-orbital multiple myeloma should be considered in the differential diagnosis of patients presenting with painful unilateral proptosis.

\section{ACKNOWLEDGEMENTS}

We would like to thank Dr. S. N. Huang who carried out immunoperoxidase staining of the surgical specimens, and Dr. Peter Pinkerton and Mrs. Velma Sachs for performing the bone marrow studies.

\section{REFERENCES}

Brenner B, Canter A, Tatarsky I, Peyser E (1982) Incidence, Prognostic Significance and Therapeutic Modalities of Central Nervous System Involvement in Multiple Myeloma. Acta. Haemat. 68: 77-83.

Clarke E (1953) Plasma Cell Myeloma of the Orbit. Brit. J. Ophthal. 37: 543.

Clarke E (1954) Cranial and Intracranial Myelomas. Brain 77: 61-81.

Fahey JL, Carbone PP (1968) Plasma Cell Myeloma with D-Myeloma Protein (IgD Myeloma). Am. J. Med. 45: 373-380.
Fishkin BG, Glassy FJ, Hattersley PG, et al. (1970) IgD Multiple Myeloma: A Report of Five Cases. Am. J. Clin. Path. 53: 209-214. Hayes JG, Peterson M, Kakulas BA (1980) Multiple Myeloma with Bilateral Orbital Infiltration and Polyneuropathy. Med. J. Australia 2: 276-277.

Humphrey DM, Aufdemorte TB, Yates GA (1983) An lgD Extramedullary Plasmacytoma Involving the Sphenoid Sinus at Onset: An Immunohistochemical Study. Laryngoscope 93(11): 1476-1480.

Jancelewicz Z, Takatusuki K, Sugai S, Pruzanski W (1975) lgD Myeloma - A Review of 133 Cases. Arch Intern. Med. 135: 87-93.

Pruzanski W, Rother I (1970) IgD Plasma Cell Neoplasia: Clinical Manifestations and Characteristic Features. Can. Med. Assoc. J. 102: 1061-1065.

Rubin P (1978) Clinical Oncology for Medical Students and Physicians, 5th Edition, p. 238. American Cancer Society, Rochester, NY.

Schulman P, Sun T, Sharerr L, Hyman P, et al. (1980) Meningeal Involvement in IgD myeloma with Cerebrospinal Fluid paraprotein Analysis. Cancer 46: 152-155.

Silverstein A, Doniger DE (1963) Neurological Compolication of Myelomatosis. Arch. Neuroi. 9: 534-544.

Stark RJ, Henson RA (1981) Cerebral Compression by Myeloma. J. Neurol. Neurosurg. Psychiat. 44: 833-836.

Trecan G Dufier JL, Blatrix C, et al. (1977) Exophthalmia maligne bilaterale d'un myelome multiple a lgM. Sem. Hop. Paris 53: 34 .

Weiner LP, Anderson PN, Allen JC (1966) Cerebral Plasmacytoma with Myeloma Protein in the Cerebrospinal Fluid. Neurology 16: 615-618.

Woodruff RK, Ireton HJC (1982) Multiple Cranial Nerve Palsies as the Presenting Features of Meningeal Myelomatosis. Cancer 49: 1710-1712. 